Sunset Western Garden Book (Brenzel 2007) and the Plant Locator (Hill and Narizny 2004), a directory of nurseries stocking particular species. While these references do not include all of the species available by mail order or via the Internet, they represent plants most commonly available in nurseries.

\section{Which plants are likely threats?}

Based on our criteria, we found 774 plants listed as invasive in other Mediterranean regions or adjacent states (fig. 1). Of these, 366 (47\%) are not naturalized in California and therefore fit our focus on potential new invaders. Of the remaining 408 species (53\%), we eliminated 318 species that did not fit our focus on new invaders: they were either native to California (Baldwin et al. 2012) or already invasive in California (DiTomaso and Healy 2007), or had naturalized in the state before 1940 without becoming invasive (Consortium of California Herbaria 2008). This left us with 90 species that naturalized after 1940.

We assumed that species that naturalized before 1940 and that have not yet become invasive in California are unlikely to become invasive in the future. Many of the naturalized species have been present in the state for over a century, with 20 recorded in the 1860s and 144 recorded before 1900 . While we believe that 70 years of naturalization without significant spread and harm is sufficient to consider a species as having low potential for invasion, this may not be true for all species. There may be some instances where longer lag periods - a length of time when a species is present in natural areas before beginning to spread and cause ecological harm - could occur prior to rapid expansion of a species. Furthermore, the movement of ornamental plants is facilitated by humans, thus increasing the opportunity for introduction to suitable habitats. In addition to possibly increasing the potential for invasion by introduced plants, this facilitation could also reduce the time between introduction and invasion.

Next, we subdivided the 90 species that became naturalized after 1940 and the 366 species that are not naturalized in California based on whether they are sold as ornamentals. We also noted whether they are sold in California (fig. 1). Of the 90 naturalized species, $70(78 \%)$ are currently sold as ornamentals somewhere in the world, with $60(67 \%)$ sold in California. Of the 366 nonnaturalized species in California, only 32\% (116 species) were ornamentals. The majority of these species $(94$, or $81 \%$ ) are currently sold in California, while the other 22 are ornamentals not sold in the state. Thus, in total, we listed 186 species of ornamentals as the greatest concern for introduction and/or invasiveness to California through the horticultural pathway. This total

\title{
EUCALYPTUS Fuel Dynamics, and Fire Hazard in the Oakland Hills
}

\begin{abstract}
Eucalyptus trees were introduced to California from Australia in the 1850 s and have become invasive in some coastal areas since then. In 1973, following a two-year study of eucalyptus stand densities, caloric content of fuel and dynamics of fuel accumulation in the Oakland Hills, researchers recommended a fuel reduction program. Eighteen years later, a firestorm in the Oakland Hills fueled by high winds and dense groves of freeze-damaged eucalyptus and pine trees killed 25 people and destroyed nearly 4,000 dwellings.
\end{abstract}

1973 "Eucalyptus has been a scenic and aromatic addition to the California landscape for over a century. The rapid growth of early plantations caught the eye of timber speculators around 1900 and millions of eucalyptus seedlings, predominately blue gum (Eucalyptus globulus) were planted. They soon covered the crest of the Berkeley-Oakland Hills, and have created a serious fire hazard since that time at the urban-wildland interface.

“... The late 1972 freeze has resulted in a proposed fuel management program for the Berkeley-Oakland Hills. Management of eucalyptus groves is an integral part of such a program. The results of this study indicate that fuel buildup occurs very rapidly in unmanaged eucalyptus stands, and to maintain low fuel levels a fuel reduction program should be implemented."

Agee JK, et al. 1973. Eucalyptus fuel dynamics, and fire hazard in the Oakland hills. Calif Agr 27(9):13-5.

Of the article's four co-authors, the two research assistants went on to distinguished professorial careers in forestry and ecological sciences, James K. Agee at the University of Washington College of Forest Resources and Ronald H. Wakimoto at the University of Montana, Missoula.

Ellis F. Darley was a plant pathologist at UC Riverside and did pioneering work on the effects of air pollution on plants and on the overall environment. At UC Berkeley, Harold H. Biswell was professor of forestry and an early proponent of controlled burning for wildland fuel management. When he retired in 1973, UC awarded him the Berkeley Citation, its highest honor for distinguished achievement. In 1994, a symposium on "Fire Issues and Solutions in Urban Interface and Wildland Ecosystems" was held in his honor.

$$
\text { -W. J. Coats }
$$

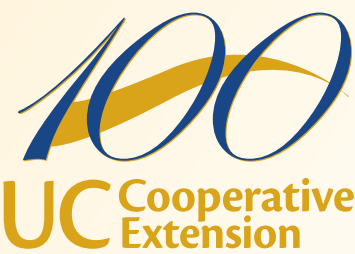

A Celebration of Science and Service 